\title{
WHAT INFLUENCES INNOVATION ADOPTION BY WATER MANAGERS? CLIMATE INFORMATION USE IN BRAZIL AND THE UNITED STATES ${ }^{1}$
}

\author{
Maria Carmen Lemos ${ }^{2}$
}

ABSTRACT: This paper examines the use of climate forecasting in water management in Brazil and the United States (U.S.). Specifically, it seeks to understand how different institutional arrangements shape the willingness and ability of water managers to incorporate technoscience, especially seasonal climate forecasting (SCF), in their decision-making process. It argues that among the many factors shaping the willingness of water managers to use SCF, institutional design and change is critical to explain different patterns in Brazil and the U.S. Moreover, factors related to individual flexibility, discretion, and accountability also affect the ability of managers to use climate information in water management. This paper finds that while water managers in the U.S operate in a mostly fragmented and risk-averse system - which constrains the adoption of innovation - decision makers in Brazil can afford more flexibility to introduce new decision tools as a result of widespread water management reforms initiated in the 1990s.

(KEY TERMS: climate forecasting; water policy; climate variability/change; water management; public participation.)

Lemos, Maria Carmen, 2008. What Influences Innovation Adoption by Water Managers? Climate Information Use in Brazil and the United States. Journal of the American Water Resources Association (JAWRA) 44(6):13881396. DOI: $10.1111 / \mathrm{j} .1752-1688.2008 .00231 . x$

\section{CLIMATE FORECASTING AND WATER MANAGEMENT}

Recent progress in the science of climate forecasting and dissemination has encouraged the idea of decision-making tools based on the ability of models to predict - in some cases with a lead time of up to a year - seasonal climate variations in different parts of the world. Such models have been particularly salient concerning the effects of the El Niño Southern Oscillation (ENSO), especially flooding and drought, in regions historically plagued by these phenomena such as Northern Peru (flooding) and Northeast Brazil (drought). Moreover, the development of user driven organizations in the United States (U.S.) and abroad such as state and federal government supported regional climate centers (Changnon and Kunkel, 1999) and the International Institute for Climate Prediction and Society (IRI) (Agrawala et al., 2001) has also increased availability and accessibility to climate data and information (for more details, see (McEnery et al., 2005).

At the same time, around the world, the current impact and possible aggravation of water scarcity have put the problem squarely on governmental and

\footnotetext{
${ }^{1}$ Paper No. JAWRA-07-0078-P of the Journal of the American Water Resources Association (JAWRA). Received June 22, 2007; accepted February 20, 2008. @ 2008 American Water Resources Association. Discussions are open until June 1, 2009.

${ }^{2}$ Associate Professor, School of Natural Resources and Environment, University of Michigan, Ann Arbor, Michigan 48109-1115 (E-Mail/Lemos: lemos@umich.edu).
} 
societal agendas. Increasingly, albeit slowly, water management has moved from a mostly technical and elite dominated affair to a process where decentralization and stakeholder participation have become persistently pursued goals. Underscored by the threat of global climate change and its potential disastrous effects on water resources, the effort to design and implement water management institutions that are democratic, economically viable, and responsive to future change has galvanized the attention of scientists and policy makers.

In principle, the use of seasonal climate forecasting (SCF) has great potential of informing decisions that lead to better planning and preparedness against potential negative impacts of climate phenomena. However, despite early optimism (Glantz, 1996), detailed empirical studies suggest that the capacity of different policy systems to use seasonal climate information in decision making can be constrained by a number of factors such as (1) access to information, communication and comprehension of probabilistic information (Nicholls, 1999); (2) lack of availability of alternative technologies and low forecast skill (geographically and temporally) (Broad et al., 2002; Kerr, 2002); and (3) the formal and informal institutional and organizational environments that shape decision making, including the various levels of government and overlapping jurisdictions involved (Callahan et al., 1999; Lemos, 2003; Rayner et al., 2005) [for a more detailed review of these constraints, see Lemos and Dilling, (2007)].

In this article, I draw a few preliminary comparisons between the use of climate forecasting information in different river basins in Brazil and the U.S. Empirical research shows that water managers are strikingly similar in both countries on the way that they make decisions and introduce new knowledge in their decision-making process. However, managers in Brazil appear to be less reluctant to embrace SCF as a tool than their U.S. counterparts. While the factors influencing greater rates of climate information adoption in Brazil and U.S. are the same - water managers in the two countries are motivated both by an increase in the "quality" of the information (including better science, communication, and "fit" to their problem solving frameworks) and by the perception of crisis to innovate - the organizational and policy environment in Brazil at the national level seems to act as an extra inducement for water managers there. In Brazil, the design and implementation of new institutional arrangements - especially participatory river basin councils may provide a new opportunity structure and more flexibility for water managers to search for new decision-support tools in the management of river basin resources. Institutional reform amplifies the salience of issues that otherwise might not be in the public or governmental agendas and facilitates networking and social learning across scales and sectors (Kumler, 2005) which in turn, may increase the visibility of new decision tools and the willingness of water managers to use them.

To advance this argument, this study relies on data collected in the context of my own research in Brazil and on excellent published work in the U.S. focusing on water managers in Southern California, the Washington, D.C. area and the Pacific Northwest (Rayner et al., 2005), South Carolina (Carbone and Dow, 2005; O'Connor et al., 2005), and the U.S. Southwest (Hartmann et al., 2002; Pagano et al., 2002).

In the following sections, I will briefly examine these issues in light of both the emergence of SCF as a decision tool and the recent reform of water management in Brazil. First, the article briefly describes a simplified framework to understand patterns of diffusion and adoption of innovation in water management taking into consideration three categories of variables at the individual, organizational, and broader institutional levels. Second, it examines water management institutional environments in Brazil and the U.S., highlighting the similarities and differences between the two systems. Third, it compares decision-making strategies and the willingness to incorporate SCF in the two policy systems. Finally, the article concludes with a few preliminary findings and suggests new areas for further research.

\section{INSTITUTIONS AND KNOWLEDGE USE}

Diffusion of innovations "refers to the spread of abstract ideas and concepts, technical information, and actual practices within a social system, where the spread denotes flow or movement from a source to an adopter, typically via communication and influence (Rogers, 1995)" (Wejnert, 2002: 297). While a rich literature focusing on the diverse concepts and processes of diffusion of innovation has emerged in the past 100 years, it has, for the most part, tended to study innovation processes in isolation. To rectify this situation, Wejnert (2002) argued for a common analytical framework where the variables and processes influencing dissemination are integrated into three main categories: characteristics of innovations, characteristics of innovators, and the environmental context where they exist.

Adapting from Wejnert's theoretical framework, I argue that in the water sector these variables can be spelled out through a simple conceptual model whose main dependent variable is the flexibility of decision 


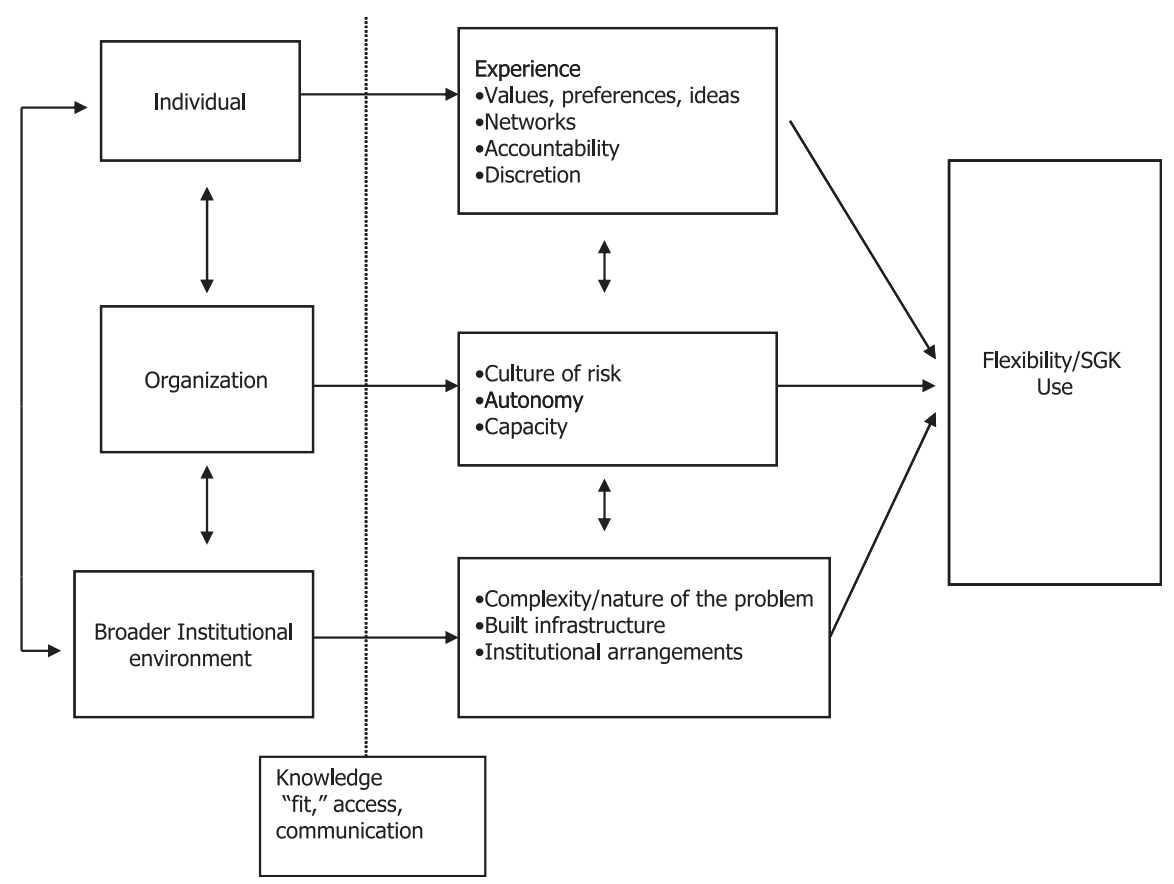

FIGURE 1. Simplified Institutional Model.

systems to adopt science-generated knowledge in general, and SCF, in particular. Figure 1 shows the simplified model.

The first column of boxes represents the three levels of institutions (formal and informal) influencing the willingness and flexibility of managers to adopt innovation. Across these three levels, communication, access to knowledge, and perception of "fit" between available knowledge and their decisions' needs affect managers' willingness to innovate. The second column of boxes represents each of the factors influencing managers' motivations to adopt or reject new knowledge into their decision-making processes. In the model, institutions refer to norms, practices, formal and informal rules and apply to both organizations and decision systems.

Regarding the character of the information (characteristics of innovations), so as to be useful to water management, climate information should "fit" managers' needs and be available in an accessible format and in a timely fashion (Lemos and Morehouse, 2005). In addition, information should also be salient, relevant, and legitimate (Cash et al., 2003).

At the individual level (characteristics of innovators), several factors shape managers' willingness to consider new decision tools. First, ideas - defined as principled beliefs affecting action (Lemos and Oliveira, 2004) - may influence an individual's willingness to use knowledge-based tools. Here managers' beliefs in terms of their mission, their clients, and the broader impact of their decisions will affect the way they perceive new decision tools. For example, in politically charged decision environments, managers may be tempted to rely on expert knowledge and "technological fixes" to insulate decision making from political meddling (Lemos, 2003). Similarly, in decision environments where managers attach high value to routine and reliability, they may avoid introducing new untested tools (Rayner et al., 2005). Second, professional background, past experiences, and the policy networks managers belong to influence the way they make decisions, either by providing examples (i.e., managers will emulate other managers) or by facilitating communication and exchange of experiences between members. Users' experience with other kinds of innovation and their outcomes will affect their willingness to experiment. Hence, users whose past experiences yielded positive outcomes will be more open to the advent of new tools (Rogers, 1995). Conversely, users who have been "burned" by innovation in the past will be less willing to try new things. Third, related to the characteristics of innovation mentioned above, the extent to which managers perceive new decision tools as relevant, credible, and legitimate may affect rates of adoption (Cash et al., 2003). Fourth, perception of risk and levels of discretion and accountability influence willingness to adopt innovation. Particularly in the case of water management, perception of risk seems to be a highly significant factor (O'Connor et al., 2005). Related with degrees of risk averseness are levels of discretion and accountability. As argued elsewhere, managers with high 
levels of discretion and low levels of accountability are likely to be considerably more willing to innovate (Lemos, 2003), as they are either able to "shift the blame" of failure elsewhere or perceive any negative consequences of their actions as unlikely to affect them or their position negatively.

At the organizational level (environmental context), the following three variables are considered: culture of risk, experience, and capacity. Like the managers themselves, some organizations will develop a higher or lower culture of risk based both on their level of discretion and accountability as well as past experiences with innovation. In addition, organizational routines are more often predicated on experience than on anticipation of the future, and experience is adapted incrementally in response to "feedback from outcomes" (Levitt and March, 1988: 320). Finally, technical and human capacities are also critical to organizations' ability to adopt innovation, that is, human and financial resources are always necessary although not sufficient to increase rates of adoption of new decision-support tools.

At the decision environment/institutional level (environmental context), flexibility may be a function of the complexity and the nature of the problem (water scarcity, water quality, and water transfer; multiple uses and conflict) and built-in infrastructure. For example, in cases where water scarcity is the main problem in the basin, decision makers may be encouraged to use climate information for planning purposes (i.e., reservoir management, water budgets for interbasin transfers, etc.) (Lemos, 2008). Similarly, the more built-in infrastructure, the more inflexible may be the system for change (Rayner et al., 2005). Finally, characteristics such as the formal institutional arrangements (legislation, nested rules, rates of institutional change) regulating water management and the informal norms and practices that influence water-related decision making critically shape the flexibility of the system to adopt new decision tools.

\section{WATER MANAGEMENT IN BRAZIL AND THE U.S.}

Both in Brazil and the U.S., water systems pose significant challenges to water managers: (1) they are subject to multiple, sometimes conflicting uses such as hydropower, fisheries, water supply, recreation, irrigation, and wastewater treatment; (2) a great number of users depend on water resources at diverse levels of need; (3) management systems cross scales and many times happen at overlapping jurisdictions; and (4) resources themselves are subject to different levels of stress, scarcity, and depletion (Rayner et al., 2005).

Yet, whereas in Brazil, water management has recently undergone a complete overhaul, in the U.S. reform has been hard to come by. Indeed, despite an impending sense of crisis, institutional change in the U.S. has mostly happened in a piecemeal and incremental fashion and the implementation of participatory models of water management has faced many obstacles (Miller et al., 1997; Stakhiv, 2003; Blomquist and Schlager, 2005).

\section{Brazil's Reform}

In the 1990s, water management in Brazil underwent an extensive reform that replaced the previous centralized, top down, and sectoral system with a decentralized, participatory, and integrated model, which adopts the watershed as the main unit of management. The reform draws inspiration from a new paradigm of water management that, among other things, is expected to increase adaptive capacity and long-term sustainability of water systems threatened by climate variability and change (Lemos, 2008).

The reform included (with variations across different states) the following: (1) the organization of management at the watershed level, overhauling a previous system that favored state and federal jurisdictions; (2) the creation of specific regulation to protect water resources at the watershed level; (3) the decentralization of decision making and resources; (4) the design of a new system of water use permits and charges; (5) the creation of different scales of public participation - especially the organization of river basin level councils and State and National Water Councils; (6) the insertion of water resources management within a larger realm of environmental concerns that challenged the traditional supremacy of economic criteria in the management of water resources; and (7) the understanding of water as a public but also an economic good - for many the most debatable and controversial aspect of the new legislation.

In Brazil's federalized system, states implemented this broad institutional design at different paces and breadths. To date there are roughly 150 river basin committees installed in the country at different stages of development (Abers and Dino, 2005). For example, in Ceará, NE Brazil, since the early 1990s, a concerted effort was put together to design a new set of institutions to manage the state's water resources. With support from the World Bank, which conditioned loans to fund new water infrastructure to the implementation of water reform, the state designed and enacted new water management instruments that 
included the creation of river basin committees, the introduction of tariffs for water users (mostly utility companies), and the creation of a water resources management company - COGERH (Companhia de Gestão de Recursos Hídricos - Water Resources Management Company) in 1993. One distinctive characteristic of the agency was the early inclusion of social scientists - mostly tasked with the organization of users to fulfill the new water resources law mandate among its personnel. Since the beginning, COGERH had an interesting blend of engineers, hydrologists, and social scientists that significantly shaped its approach to water management (Lemos and Oliveira, 2004).

In the Lower Jaguaribe-Banabuiú river basin, COGERH is in charge of reservoir management with the support of two participatory councils. The first is the Users' Commission that meets periodically to evaluate and plan for water use of the river basin's three main reservoirs. As a decision support tool, técnicos as local managers are called - from COGERH build simple reservoir scenarios where different rates of discharge are represented. Although zero rainfall is built into the scenarios, técnicos use climate information (especially ENSO forecasting) to modulate how conservative their advice to users will be during the public meetings (Interviews with several technical personnel at COGERH between July 2001 and August 2004).

In these meetings, water users engage in heated debates in which they try to reconcile their water needs with water availability according to the different case scenarios provided by COGERH. For example, in a meeting I attended in June 2001, a year of drought, the debate was around the possibility of an extended event and the need to decrease water use especially by irrigated rice farmers. In this preliminary meeting, an incipient consensus around the need to reduce rice production by $50 \%$ (one yield instead of two a year) started to form among rice growers and other water users [for more detail on the evolution of this negotiation see Formiga-Johnsson and Kemper (2005)]. The second council is the more formal River Basin Committee formed by a tri-party membership representing water users (1/3), government (1/3), and organized civil society (1/3). Recently, these two councils have merged and the negotiation for water allocation has been transferred to the jurisdiction of the River Basin Committee (Renzo Taddei, personal communication, November 29, 2007) (for a detailed analysis of the use of SCF in the context of water allocation, see Lemos, 2008).

In another river basin, the Paraíba do Sul River (PSRB) which crosses Brazil's three most developed states (Rio de Janeiro, Minas Gerais, and São Paulo), reservoir management has been much less participa- tory although the post-water reform decision-making process can be considered significantly more transparent than in the past (Kumler, 2005). The PSRB system is one of the most institutionally complex in Brazil; within the PSRB, one contentious issue is the transfer of water resources across basins, from the river's headwaters in the state of São Paulo to the city of Rio de Janeiro (located outside the basin) through a system of reservoirs and dams. Besides supplying $80 \%$ of all water to the city of Rio de Janeiro, the system also generates electricity as part of Brazil's energy matrix and normalizes river flows to control flooding. Historically, the management of water resource transfer has been under the control of the electrical sector with virtually no participation from other stakeholders. In the 1998, the sector created and financed an independent, private agency the National Electric System Operator (Operador Nacional do Sistema Elétrico - ONS) to control the flow of water. ONS has been one of the most proactive users of climate information in water management in Brazil, including long-term forecasts - used in infrastructure planning (ONS 2002).

In the early $2000 \mathrm{~s}$, after three years of persistent drought and with reservoirs getting dangerously low in the region, it became clear that some level of renegotiation of the levels of water transfer would be necessary if open conflict between São Paulo and Rio de Janeiro was to be avoided (CEIVAP committee member, personal interview, August 8, 2004). The CEIVAP technical chamber decided to create a task force to examine and open the discussion of possible scenarios for change to stakeholders beyond the electrical sector. The group met several times with ONS in Rio de Janeiro and negotiated for the first time a reduction in the amount of water transferred to the city. The decision not only considered both the water supply needs of Rio but also the likelihood that the drought could last longer (CEIVAP committee member, personal interview, August 8, 2004).

Although neither COGERH nor ONS use climate forecasting operationally, they are both actively seeking to increase their use of climate information both through building partnerships with organizations such as IRI and by commissioning research groups within Brazilian universities to build downscaled models that could be incorporated at decision-support tools at the basin level.

\section{Management in the U.S.}

Regarding the use of SCF in water management in the U.S., many scholars of the subject (Pulwarty and Redmond, 1997; Callahan et al., 1999; Carbone and Dow, 2005; Rayner et al., 2005) agreed that the U.S. 
system has been traditionally risk-averse and constrained by a series of factors cutting across most water systems: (1) water managers are heavily constrained by institutional arrangements such as water laws, related regulations, institutional linkages, local politics, inter-agency competition, etc., which make water management systems inflexible and resistant to the introduction of new decision-making technology; (2) water decision-making systems are greatly fragmented and complex, spanning from multiple scales and many times conflicting jurisdictions; (3) change is hard to implement because of inertia built into the system by large and expensive infrastructure, private interests, and regulatory agencies; (4) current state-of-the-art climate forecast information is perceived as too uncertain, lacking in geographical and temporal specificity, lacking in interpretation and demonstrated utility, and too unreliable (low skill) to water managers' decision-making needs; and (5) there is still a significant disconnect between information producers and users.

Rayner et al. (2005, p. 207) argued that this conservatism among water managers has its roots in three sources: "the evolution of their function of the routinization of the irregular, their dependency on craft skills and local knowledge, and their hierarchy of values designed to ensure political invisibility." Routinization of the irregular refers to water management's goal to attenuate the impact of weather or other factors that may threaten water quantity and quality. Accordingly, the system strives to control as much of the process as possible and avoiding irregularity becomes part of the routine of management. Second, water systems are widely diverse and perceived to be sensitive to local conditions. In this scenario, managers perceive local experience and knowledge as a highly desirable function. Finally, because of the high expectations of the public regarding water supply and quality, managers perceive themselves as greatly accountable and strive to achieve public invisibility. Indeed, Rayner et al. (2005) reported that performance expectations generate the following hierarchy of values for managing water resources: reliability, quality, and cost.

Conservatism means that water agencies, such as other public agencies, mostly change slowly through incrementalism or adaptive management rather than radical change (Stakhiv, 2003). In this context, it is not surprising that water managers express great reluctance in introducing new tools they perceive as unproved by their day-to-day experience. Moreover, negative experiences from other systems, which dare to experiment, can potentially exacerbate managers' resistance to climate forecasting (Pielke, 1999; O'Connor et al., 2005). Empirical evidence show that a very small number of water managers report that they actually use climate forecasting, although a larger number express interest in using it in the future (which Rayner et al. suggested may be more than 20 years ahead). However, there is also evidence that willingness to use SCF is heavily modulated by perception of risk and impending crisis (Hartmann et al., 2002; O'Connor et al., 2005), that is, when confronted by crisis, water managers' willingness to use SCF may increase significantly. As I describe in the next section, the situation is different in Brazil where despite a focus on reliability, quality, and cost, managers seem to be less constrained by accountability and its potential negative consequences.

\section{Flexibility, Accountability, Institutional Change, and Water Management}

A first approach comparison suggests that although the institutions of water management in Brazil and U.S. seem quite distinct, at the decisionmaker level, there are consistent similarities. To compare with the U.S. study, a questionnaire for in-depth interviews with water managers was applied in Brazil (in Ceará, Rio de Janeiro, São Paulo, and Minas Gerais) in the summer of 2004 and 2005. The questionnaire included similar questions to the one applied by Rayner et al. in their case studies in the U.S., including queries about manager's background (education, professional history, values, and experience), use of technoscientific information (including means of access, selection and evaluation of knowledge, perception of "fit", and previous experience with innovation), and detailed mapping of opportunities and constraints for adoption of innovation at the individual, organizational and policy levels. Differently from the U.S. project, in addition to water managers other decision makers such as hydroelectric sector and disaster response managers were also interviewed in Brazil. Finally, data were also collected through participant observation of river basin committee meetings in the two basins.

Data from the questionnaire show that managers in Brazil share many of the perceptions of their job description and goals and are driven by comparable motivations as their U.S. counterparts. Hence, the majority of managers interviewed in Brazil considered that client satisfaction was their main motivation and that a functioning, reliable system was the main goal of their job. They perceive their work as eminently technical and nonpolitical and take pride in their invisibility. They also reported that climate data were mostly available and accessible through the Internet and meteorology agencies in their regions.

In addition, the majority described their organizations as open to innovation and up to date with the 
current technology in the field despite lack of financial resources. Responses regarding their willingness to use climate information were mixed. Many would like to have a better idea of the reliability of the forecasts to be able to make better-informed decisions. While some managers interviewed (especially from water utility companies) were intrigued by the idea of climate forecasting but did not identify a specific use for this kind of information in their decision-making processes (as their access to water is mostly defined by managers elsewhere), others (particularly in areas related to drought planning such as water management, agriculture, and civil defense) were more enthusiastic about the potential of climate forecasting to inform their decisions. There was also frequent mention of the great potential of the information to improve decision making as its "quality" (better temporally and geographical skill) improves.

One difference between water managers in Brazil and the U.S. seems to be their level of discretion and accountability. This was particularly true in the case of managers who were in charge of smaller, nonstrategic reservoirs in drought-ravaged regions. For example, one manager reported that many times he would authorize discharge of water from some reservoirs until they virtually empty out. When asked if he did not fear a negative reaction from clients, he responded, "well, people here understand: If there is no water, there is nothing I can do. At least now, with all other resources, people don't die as much as they did in the past." (Reservoir técnico, personal interview July 2002, my translation).

Although he was an exception in his willingness to take risks - most managers are quite conservative and risk averse - when compared with the water managers studied by Rayner et al. (2005), decision makers in Brazil seem to be somewhat less constrained by accountability. For example, the winter of 2001 found Brazil immersed in one of the worst energy crisis in the country's history. To respond to the crisis, the federal government implemented a mandatory decrease of $20 \%$ on the average consumption of each household, business, and government agency. The crisis was the result of a combination of lack of rainfall and a succession of myopic planning dating back to the military dictatorship. Although politically costly, the crisis did not seem to hurt management positions significantly; rather, there was an attitude of outraged acceptance that appeared to hurt politicians more than managers. Lack of accountability also reflects a tradition of technocratic insulation - that is, the ability of decision makers to hide behind their technical expertise to make decisions virtually unchecked by the wider public - that has historically shaped public policymaking in Brazil (Lemos, 2003). Hence, while in the U.S., high accountability lead managers to strive for invisibility, Brazil's technocratic tradition may insulate managers and "cushion" their accountability.

Finally, the significant difference between the formal institutional arrangements shaping water management in Brazil and the U.S. also plays a role. As mentioned before, whereas Brazil has undergone encompassing reforms that have created a national water policy, the U.S. continues to struggle over a fragmented and many times contradictory water management system (Stakhiv, 2003). The Brazilian system, however, although based on national regulation, has followed a highly federalized model that has afforded much flexibility to states to design and implement institutions that better "fit" the characteristics of their water resources and socio-political systems. Within this rather loose institutional framework, managers may afford greater degrees of freedom not only to create new institutions but also to change the existing ones.

\section{CONCLUDING REMARKS AND MORE RESEARCH}

The emergence of climate forecasts as a policy tool has encouraged the production of a steady-stream of scholarship speculating and evaluating potential roles of such information in decision making. This article seeks to understand a few of the factors affecting the use of climate forecasting in policymaking from a comparative perspective. It finds that among the many variables shaping the potential for the use of climate forecasting by water managers in Brazil and the U.S., institutional environment is critical. While water managers in the U.S. and Brazil share many similar characteristics and perceptions, the institutional arrangements shaping their decision making environment vary considerably. In the U.S., water management is mostly characterized by a fragmented and risk-averse system where the most sought after outcome is reliability and stability. Whereas in Brazil, water managers also worry about reliability, they seem to have considerably more discretion and be willing to take more risks than the U.S. water managers described in this study. Although there are many other variables affecting water resources management in the two countries, this article contends that one critical reason for such disparity is the higher level of institutional change in Brazil where a widespread reform of the water management system has been initiated in the 1990s. In this case, the change of the basic water management paradigm in Brazil provided actors and organizations with greater degrees of freedom both to create new institutions that better "fit" 
their water resources and their users management needs as well as to incorporate new technologies in the decision-making process. Hence, the new system adopted a jurisdiction for decision making - the watershed - and created a number of organizations such as the Users Commissions and River Basin Committees that significantly decentralized decision making and stimulated user participation.

Still, this preliminary comparison is just the first step of a much broader research effort required to understand the use of technoscience in policymaking across systems. More research is needed focusing both on organizational, informational, and institutional variables (e.g., the role of the quality and relevance of forecasting information, the "character" of the organizations producing and using forecasting, broader socioeconomic and political variables shaping the decision making arena, etc). Systematic data collection through in-depth interviews and surveys of managers and users needs to be carried out in different watersheds if we are to improve our understanding of the potential of climate forecasting as decision making tool.

\section{ACKNOWLEDGMENTS}

This on-going research is funded by grants from the National Science Foundation (Award \#SES 0233961) and the National Oceanographic and Atmospheric Administration (Award \#NA03OAR4310010). Preliminary, ethnographic field research has been carried in Ceará, NE Brazil and Southeast Brazil (Sao Paulo, Rio de Janeiro, and Minas Gerais) where water managers, river basin committee members, and a few managers of the electric sector who are active participants of reservoir management were interviewed for two consecutive summers (2003-2004). I want to thank them for their generous sharing of knowledge with me. Finally, I would like to thank Marcelo Flores and Rosa Formiga for their assistance in collecting data in Brazil and Lori Kumler for carefully reading the manuscript.

\section{LITERATURE CITED}

Abers, R.N. and K.J. Dino, 2005. Descentralização da Gestão da Água: Por que os Comitês de Bacia Estão Sendo Criados?. Ambiente e Sociedade. 8(2):99-124.

Agrawala, S., K. Broad, and D. Guston, 2001. Integrating Climate Forecasts and Societal Decision Making: Challenges to an Emergent Boundary Organization. Science, Technology and Human Values 26:454-477.

Blomquist, W. and E. Schlager, 2005. Political Pitfalls of Integrated Watershed Management. Society and Natural Resources 18:101117.

Broad, K., A.S.P. Pfaff, and M.H. Glantz, 2002. Effective and Equitable Dissemination of Seasonal-to-Interannual Climate Forecasts: Policy Implications From the Peruvian Fishery During El Niño 1997-98. Climatic Change 54(4):415-438.

Callahan, B., E. Miles and D. Fluharty, 1999. Policy Implications of Climate Forecasts for Water Resources Management in the Pacific Northwest. Policy Sciences 32:269-293.
Carbone, G.J. and K. Dow, 2005. Water Resources and Drought Forecasts in South Carolina. Journal of the American Water Resources Association 41(1):145-155.

Cash, D.W., W.C. Clark, F. Alcock, N. Dickson, M. Eckley, D. Guston, J. Jäger, and R. Mitchell, 2003. Knowledge Systems for Sustainable Development. Proceedings of the National Academy of Sciences of the United States of America 100(14):8086-8091.

Changnon, S.A. and K.E. Kunkel, 1999. Rapidly Expanding Uses of Climate Data and Information in Agriculture and Water Resources: Causes and Characteristics of New Applications. Bulletin of the American Meteorological Association 80(5):821830.

Formiga-Johnsson, R.M. and K.E. Kemper, 2005. Institutional and Policy Analysis of River Basin Management in the Jaguaribe River Basin, Ceará, Brazil. Policy Research Working Paper 3649. World Bank, Washington, D.C, 42 pp.

Glantz, M. 1996. Currents of Change: El Nino's Impact on Climate and Society. Cambridge University Press, Cambridge, England.

Hartmann, H.C., T.C. Pagano, S. Sorooshian, and R. Bales, 2002. Confidence Builders: Evaluating Seasonal Climate Forecasts From User Perspectives. Bulletin of the American Meteorological Society 8:683-698.

Kerr, J., 2002. Watershed Development, Environmental Services and Poverty Alleviation in India. World Development 30(8):1387-1400.

Kumler, L.M. 2005. Old Institutions and New Approaches to Sustainability: Creative Cooperation in Managing Waters of the Paraíba do Sul Basin. Unpublished Master's Thesis, School of Natural Resources and Environment, University of Michigan, Ann Arbor.

Lemos, M.C., 2003. A Tale of Two Policies: The Politics of Seasonal Climate Forecast Use in Ceará, Brazil. Policy Sciences 32(2):101-123.

Lemos, M.C., 2008. Whose Water Is it Anyway? Water Management, Knowledge, and Equity in NE Brazil, In: Water and Equity: Fair Practice in Apportioning Water Among Places and Values, R. Perry, H. Ingram, and J. Whiteley (editors). MIT Press, Cambridge, Massachusetts, pp. 249-270.

Lemos, M.C. and L. Dilling, 2007. Equity in Forecasting Climate: Can Science Save the World's Poor? Science and Public Policy 34(2):109-116.

Lemos, M.C. and B. Morehouse, 2005. The Co-Production of Science and Policy in Integrated Climate Assessments. Global Environmental Change 15(1):57-68.

Lemos, M.C. and J.L.F. Oliveira, 2004. Can Water Reform Survive Politics? Institutional Change and River Basin Management in Ceará, Northeast Brazil. World Development 32(12):2121-2137.

Levitt, B. and J.G. March, 1988. Organizational Learning. Annual Review of Sociology 14:319-340.

McEnery, J., J. Ingram, W. Duan, T. Adams, and L. Anderson, 2005. NOAA's Advanced Hydrologic Prediction System. Bulletin of the American Meteorological Society 86(3):375-385.

Miller, K.A., S. Rhodes, and L.J. McDonnel, 1997. Water Allocation in a Changing Climate: Institutions and Adaptation. Climatic Change 35:157-177.

Nicholls, N., 1999. Cognitive Illusions, Heuristics, and Climate Prediction. Bulletin of the American Meteorological Society 80(7):1385-1396.

O'Connor, R.E., B. Yarnal, K. Dow, C.L. Jocoy, and G.J. Carbonne, 2005. Feeling at Risk Matters: Water Managers and the Decision to Use Forecasts. Risk Analysis 5:1265-1275.

ONS, 2002. Sub-Modulo 9.6 - Disponibilização de Informações Meteorológicas e Climáticas. Operadora Nacional do Sistema. http://www.ons.org.br.

Pagano, T.C., H.C. Hartmann, and S. Sorooshian, 2002. Factors Affecting Seasonal Forecast use in Arizona Water Management: 
A Case Study of the 1997-98 El Nino. Climate Research 21(3):259-269.

Pielke, Jr., R., 1999. Forecasts and Responsibilities in the 1997 Red River Flood. Applied Behavioral Science Review 7(2):83-101.

Pulwarty, R.S. and K.T. Redmond, 1997. Climate and Salmon Restoration in the Columbia River Basin: The Role and Usability of Seasonal Forecasts. Bulletin of the American Meteorological Society 78(3):381-396.

Rayner, S., D. Lach, and H. Ingram, 2005. Weather Forecasts are for Wimps*: Why Water Resource Managers do not Use Climate Forecasts. Climatic Change 69:197-227.

Rogers, E.M., 1995. Diffusion of Innovation. Free Press, New York.

Stakhiv, E.Z., 2003. Disintegrated Water Resources Management in the U.S.: Union of Sisyphus and Pandora. Journal of Water Resources Planning and Management 129:151-154.

Wejnert, B., 2002. Integrating Models of Diffusion of Innovations: A Conceptual Framework. Annual Review of Sociology 28:297326. 